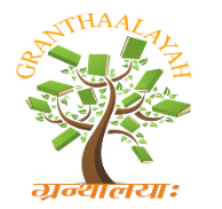
INTERNATIONAL JOURNAL OF RESEARCH
GRANTHAALAYAH
A knowledge Repository

Management

\title{
THE ECONOMIC OF SCAVENGING BUSINESS IN MUBI METROPOLITAN AREA
}

\author{
Adamu Yahaya*1 \\ ${ }^{* 1}$ Department of Economics, Faculty of Social and Management sciences, Adamawa State \\ University, Mubi, PMB 25 Mubi, Adamawa State, Nigeria
}

\begin{abstract}
The study examines the economics of scavenging (Baban Bola or Yan Bola), in Mubi by over increasing numbers of unemployed youths in Mubi. The data was collected through closed ended questionnaires (60) and through researcher field observation. Data obtained were qualitative and quantitatively analyzed using descriptive statistic. Result shows that materials scavenging from solid waste for recycling is dangerous done by combining through waste dumps where materials sought after handpicked. Recyclable materials are also obtained by scavengers through the process of weighing or pricing. The materials required are hence transported using a metal cart (push push) to junk collection deport and processed by sorting and grinding. They are consequently weight using the salter scale to determine their monetary worth before selling it to the junk dealers. Most materials collected by scavengers are metallic objects, glass bottles, rubbers or plastic material because demands for such materials are high by recycling industries locally. This scavenging practice is observed to by environmentally being as it helps in reducing the excess waste destined for evacuation and final disposal in addition to the job it creates. It is however, recommended that scavenging practice should be properly organized and practitioners financially empowered so that they will acquire modern tools of resources recovered from waste to bust their capacity to recover more waste which will in due course lead to low-waste society.
\end{abstract}

Keywords: Scavenging; Metropolitan; Economic.

Cite This Article: Adamu Yahaya. (2018). "THE ECONOMIC OF SCAVENGING BUSINESS IN MUBI METROPOLITAN AREA International Journal of Research - Granthaalayah, 6(7), 191-199. https://doi.org/10.29121/granthaalayah.v6.i7.2018.1298.

\section{Introduction}

\section{Background of the Study}

Municipal solid waste management practices are the techniques or methods employed by urban dwellers in the collection, storage, transportation and disposal of solid waste generated from day to day activities. MSW is troublesome to manage because it consist of diverse range of materials such as glass, metals, plastics, papers, food, nylon, vegetable, deed animals etc. (Afon, 2003). 
Wikipedia (2012) describes a waste picker (scavenger) as a person who salvages reusable or recyclable materials thrown away by others to sell or for personal consumption. Such practice eliminates a lot of materials that may be dumped, burnt or buried as waste. This goes to say that if what constitute our waste is segregated and their uses found, they can be good sources of raw materials for our cottage industries, generate employment and income, and equally rid our cities of refuse dumps or reduce our waste stream destined for final disposal.

Mubi metropolis located in the northern part of Adamawa state, Nigeria, and lies between latitude $10^{0} 14^{`}$ and $10^{\circ} 18^{`}$ north of the equator and longitude $13^{\circ} 19^{`}$ east of the Greenwich meridian (Adebayo, 2004) is one place where a new wave of commercial waste scavenging exist. Armies of scavengers throng refuse dumps and the streets daily collecting reusable or recyclable waste materials of commercial value. It is in this light that this study attempts an assessment of the emergent form of resource recovery, commercial waste scavenging practices in the study area.

The research is therefore, is aimed at finding out the economics of scavenging on employment and income generation in Mubi. The scope of the paper is however, narrowed to Mubi.

The research is therefore, organized into four parts, after the introduction part two reviewed literature and theoretical issues, part three contain the results and the last part contain concluding remarks.

\section{Methodology}

The methodology that is employed is the use of both primary and secondary source of data. The primary data is gathered through oral interview with scavengers. A survey was conducted among scavengers in order to find out the hours they spent and income earned from their activities. Some dumpsites were visited so that information was gathered too. Sixty scavengers were interviewed in four types of areas that is residential areas, commercial areas and at dumpsites. Additionally, group discussions were held to enable respondents to talk more freely about their activities and the social conditions. The outcome of the interview is analyzed in section three. Secondary data was collected through the review of textbooks, journals, published seminar papers, and reports of commission the internet and other published materials.

A research into economic of scavenging practices requires collecting relevant information from focus groups notably scavengers and their likes in the study area. The information collected forms the research data. Data on the transportation/trips and marketing of scavenged materials by scrap merchants to recycling factories/foundries and items made out of the scraps were also obtained and analyzed.

The use of descriptive statistics such as, frequency distribution tables, percentages, ratios and averages on one hand and inferential statistics such as correlation analysis are employed in the course of analyzing the collected data. The adoption of this technique is to find out the average income generated by scavenging as well as the average number of people that engaged in waste employed by the profession. 
Close ended questionnaire was distributed to respondent in Mubi area and seven people were interviewed. In the area simply, random sampling is used to select the seven people interviewed. This sampling techniques were adopted so that the respondent will have the same chance of been selected.

\section{Review of the Existing Empirical and Theoretical Issues}

The picture of scavenging that emerges from reviewing literature is that of an occupation that provides a livelihood for the poor. Scavenging is an important survival strategy in which impoverished individuals coped with scarcity. Scavengers typically specialize in recovering only one or a few types of materials from waste. To Medina (1997) Scavenging takes place in all stages along the waste management system that is; source separation at household or place generating waste material; here materials are reused, sold or given away examples old newspapers are used for packing. During collection, scavengers sort out recyclables for sale. Scavengers also retrieve recyclables at dumps, on the streets or public places, in canals and rivers, at landfills prior to burial and purchased source separated recyclables from residents.

Scavenging is ubiquitous occurrence throughout the developing world. The World Bank has estimated that up to $2 \%$ of the population in third world countries survives by recovering materials from waste. Scavengers salvage materials to sell for recycling, as well as repairable and re-usable items that can sell or use themselves. The recovery of materials from waste by scavengers in developing countries takes place in a wide variety of settings, although the circumstances in which materials are recovered in a particular place may be different. From the above one can say that scavengers source their materials from two major ways that is either sorting or collecting freely from dumps and landfills, or by buying the already sorted materials from households.

Poverty prevalent in most developing countries forces the poor to make the most of the resource available to them. Given their very low incomes, scavenging provides them with reusable and salable materials. In doing so, the poor have developed creative ways in order to satisfy their needs, including the recovery of items not necessarily part of the waste stream.

In Mali many farmers search and dig artifacts produced by ancient Mali Empire in order to sell them to art collectors (Brentt, 1994; French, 1995). In Calcutta scavengers work along the rail road tracks in order to recover the pieces of coal that fall from the train (Lapierre, 1985). In Cairo scavengers search ox dung for undigested kernels of corn to eat (Linden, 1993). In Vietnam scavengers dig on agricultural fields and jungles, searching for scrap metal left over from the war (Donohue, 1994).

\section{Characteristics of Scavenging}

The following characteristics can be generalized for scavengers;

That is, scavengers are poor relative to the rest of the society, their incomes are low, scavenging is an informal activity and labour intensive in nature, scavenging can render economic and social benefits (such as; work for the unemployed individuals, supply raw materials for industry etc.), scavenging generate cost to society such as high health risk associated with the type of labour, scavenging supplies raw materials largely to either artisans or industry, in dumpsites located near 
agricultural areas, scavengers recover organic materials to be used as fertilizers as well as food for goats and pigs.

\section{Economic Impacts of Scavenging}

Scavenging contributes to reduce the amount of solid waste to be disposed and also helps to save the natural resources that leads to sustainable development. It creates jobs and extra income for people especially the poor. Scavenging encourage family members to sort out materials from wastes in exchange for money. Besides it supply raw materials for a lot of recycling enterprises and this creates more jobs for people as well as useful products for the society. Scavenging renders economic and environmental benefits, such as providing income to unemployed individuals, supply inexpensive raw materials to industries, reduce the demand for collection, transport and disposal equipment and facilities. Further material recycling has a lower environmental impact that is accelerated by scavengers.

Various studies have highlighted the economic significance of scavenging activities. Loan (2002) studied the social impacts of solid waste recovery and recycling in Hanoi, Vietnam. The recovery system according to his findings consisted of collectors, buyers and traders. Collectors gather materials from three groups of sources; dumping grounds, (dumpsite scavengers, in the public places, (itinerant scavengers) and in-house places (itinerant junk buyers). The materials from scavengers and junk buyers are bought by group of depot operators at dumping grounds and within the city. About 6000 people are working in the scavenging field. They came mainly from the rural areas, the largest group within the labour force are those under 20 years old (25\%), adult male (31\%), and adult female (44\%). the system create jobs and extra income as it mobilizes all family members to work. On the other hand the negative side of the recovery system is that it encourage illegal immigration of rural people into the city to live in a bad condition and hence vulnerable to diseases and epidemics.

Diaz (2000) argued that Scavenging is a process that is well practiced in developing countries, in fact scavenging is a source of employment, that attempt made to abolish the practice in some cities have been met with strong resistance. Scavengers roam the streets looking for items that can be reused, other scavengers conduct their activities at disposal sites. Generally scavengers have an agreement with a middle man, and the middleman is an individual who has contract with end users, who can process, prepare and sell the quantities of materials desired by users and he provides the scavengers with compensation and in some cases a collection vehicle (e.g. a cart). The families and social background of scavengers are such that scavenging is the only option available to them to earn a living. In most developing countries scavenging played important role on the economic survival of a number of industries (e.g. steel, pulp and paper)

Ado (1998) studied the economic importance of solid wastes in Kano metropolis his findings showed that on the average scavengers that buy recyclables from households generate an income that is equivalent to $50 \%$ of the cost of purchase (e.g. for each recyclable they bought at N1.00, they would get $50 \mathrm{k}$ as profit). He went ahead to conclude that scavenging provided employment to youth that are hitherto not employed, besides these scavengers have been responsible for the separation of waste materials and in some cases upgrading it through washing for the recycling industries. 
In an effort to study the recycling efforts of industries in Kano Adisa (2000) studied 60 respondents and find out that; the scavengers in Kano state are not organized in any formal way, yet their contribution to economic growth is significant. The scavengers are of two type namely; the primary and secondary scavengers. The secondary scavenger gave the primary scavenger a token amount of money to buy recyclables from the neighboring areas and in return, the materials are weighed and priced accordingly. A kilogram of rubber shoes or plastic on the average costs $\mathrm{N} 22-\mathrm{N} 30$, and the companies that recycle these materials includes Balley plastic, and Standard plastic. On the average a secondary scavenger employ 6 primary scavengers or more, by doing this, a lot of youth are employed by the profession. On the problem that is facing scavengers he found out that; scavengers do not receive any assistance from the government, and the worst of all is that government levy heavy taxes on the secondary scavengers who are mostly salvage dealers.

\section{Scavenging and Surplus Value}

Using the Marxist perspective Birkbeck (1979) analyzed labour issues of scavengers in Columbia. He described the situation in terms of self-employed informal sector workers, who like factory laborers, engaged in piece work of which the surplus benefited the middlemen. The relationship between scavengers, the middlemen (salvage dealers) and factories can however, be characterized as Patron - client relationship based on mutual trust and cemented by rather stable product delivery and money lending patterns. These relations reduce the vulnerability of the scavengers by Guaranteeing a certain security of living, albeit at a low standard, as the middleman use this dependence to fix prices of the recovered materials at very low level. Because of this basic survival strategy, the scavenging system was described by Singular (1992) as hunting and gathering societies, who survive under conditions of common source exploitation. They gather 'ores' and hunt for 'valuables' in the same way as hunters and gatherers use forests and planes. The exploitation of scavengers by middlemen occurs through market relations and not by means of employment relations as in a capitalist industrial setting. The informal production relations of scavengers are intertwined with the formal sector since they paid various types of taxes to government.

Waste scavenging in Mubi metropolis represents an adaptive response to chronic poverty; however the benchmark appeared to be the structural adjustment programme (SAP), when barn was impose for the importation of some industrial inputs with the objective of making the economy to be diversified and self-reliant. Waste scavenging in Mubi has contributed to the development of the informal sector by providing a labor-intensive, low technology and low paid activity. scavenging have also rendered economic and environmental benefits such as work for unemployed individuals, supply of cheap raw materials to industries, reduces the demand and cost for waste collection, transport and disposal equipment facilities.

\section{Results and Discussion}

As have been mentioned in the methodology a total of sixty scavengers were interviewed, this section will present and analyze the responses. The profile of scavengers interviewed is represented. Out of the total number of 60 scavengers interviewed 57 are males while only 3 are females. Since respondents are selected at random, it can be deduced that scavenging in Mubi metropolis is not equally divided between male and female, this account for bias in favor of males. 
The bias may perhaps be due to the culture and religion that is prevailing in the study area which restrict females especially married women from coming out to scavenge for useful materials. The above figure also showed that $65 \%$ of the respondents are 30 years old or younger. Of this young workforce $45 \%$ of the sample was children of 15 years or less. The drop-out rate from the workforce particularly is pronounced at the age of 40. An explanation for this phenomenon may be that, scavenging is a profession that requires young and energetic people who can work the length and breadth of the city to search for useful materials. No female scavenger was recorded from the age of 15 years or less.

The illiteracy rate among the respondents was $70 \%$. Only 15 scavengers had some knowledge of formal education and they are all primary school drop outs between classes $2-5$. Therefore, we can conclude that scavenging in Mubi is practiced mainly by those with no formal education. Another important finding is the dominance of immigrants from villages in to the profession. All the 60 scavengers interviewed are however, Muslims and this may be due to the location of the study area.

\section{Reason for Waste Scavenging}

The various reasons that attracted the people into scavenging are represented below.

From the research made scavengers are into the profession due to income and employment it provides to them, $27 \%$ joined scavenging due to poverty, while $20 \%$ are due to their low social status which includes lack of shelter, education orientation and parental care. The last category practiced scavenging due to personal interest, by chance and some of them say they don't know the reason. $65 \%$ are into scavenging because of economic reasons (poverty, income and employment). Majority of the waste pickers lived with their families and contributed to household income. It was observed that young children usually accompanied their fathers from an early age.

\section{Types and composition of materials recovered}

Table 1: Composition of domestic waste in Mubi metropolitan area

Source: Field survey, 2017

\begin{tabular}{|l|l|}
\hline Materials & \% Composition. \\
\hline Plastic/Rubber & 43.7 \\
\hline Metals/Iron & 22.2 \\
\hline Glass Bottles & 20.1 \\
\hline Others & 14.0 \\
\hline
\end{tabular}

From the above table it can be seen that the major type of materials recovered by scavengers are plastics, metals, glass bottles and others. The materials categorized under others were identified to be old car batteries, used grain bags, papers, rags, wood, Catton and so on. The source where the scavengers got these materials are mainly two; namely open dumps that are considered to be no man's land and households. In case of materials from the households a token amount is being given in exchange for a recyclable material, sometimes new plastic plate, matches box, plastic bucket are given to the household members in exchange. 


\section{Average Hours Worked}

Working hour in any profession is very crucial in determining the extent to which a particular economic activity contributed towards employment provision.

Table 1: Hours worked by scavengers.

\begin{tabular}{|l|l|l|}
\hline Hours worked & Frequency & Percentage \\
\hline Less than $3 \mathrm{hrs}$ & 12 & 20 \\
\hline $4-6$ hrs. & 16 & 27 \\
\hline $6-12$ hrs. & 32 & 53 \\
\hline Total & 60 & 100 \\
\hline
\end{tabular}

Source: Field survey, 2017

From the table above we can see that $20 \%$ of the sampled scavengers worked for 3 hours or less, $27 \%$ worked for $4-6$ hours, while 53\% worked for $6-12$ hours. It can be concluded therefore, that more than half of the scavengers worked for the whole day. It was observed that on the average scavengers worked between the hours of $8 \mathrm{am}$ to $6 \mathrm{pm}$ that is 10 hours in a day.

Table 2: Average price of materials collected by scavengers

Source: Field survey, 2017

\begin{tabular}{|l|l|}
\hline Type of Materials & Price in Naira. \\
\hline Plastic & 30 per kg \\
\hline Metal/iron & 55 per kg \\
\hline Used 5litre plastic gallon & 10 per 1 \\
\hline Old car battery & 50 per 1 \\
\hline Soft drinks bottles & 5 per 1 \\
\hline
\end{tabular}

The table above presents the prices of various type of recovered materials by scavengers state, these prices are however, offered by the salvage dealers who later take the products to the recycling enterprises. These salvage dealers are located at specific depots in Wuro patuji, Arhan kunu, Mundang, Agwan kara and Tudun wada, Va'atita areas all in Mubi metropolis. Metals/Iron and Old car battery have a higher value and hence a higher earning potential. Soft drinks bottles though are very heavy have a lowest price. Plastic and used plastic gallon however, have moderate price. The average quantity of waste materials collected by a scavenger in a day was estimated to be $15 \mathrm{~kg}$. The average daily income of a scavenger was estimated to be N600; it was also observed that male scavengers earn more than their female counterparts. Finally it was discovered that in some cases scavengers recovered materials and used it for their personal use, these materials include fire wood and clothes. It should be noted that the items that are recovered and used for personal consumption by scavengers are not included in the estimation of scavenger's total earnings.

A correlation analysis was conducted in order to find out the factors that determines the income of scavengers. Hour of work and earnings were tested, and the coefficient of correlation showed that the two variables are uncorrelated at all. Age of scavengers and earnings were tested too, and it was found out that the correlation was very negligible. A strong relationship was however, 
observed between area of operation and earnings of scavengers. In higher income areas like the government reserve areas (GRA) scavengers found more useful materials in dumps, this is due to the fact that households located in higher income areas do not care to collect useful materials from their waste before discharge, by and large their consumption pattern and nature of the products consumed is another contributing factor. These findings suggest that scavenging is an unorganized activity that requires little or no skill.

Table 3: Estimated income Generated by scavengers in Mubi.

Source: Field survey, 2017

\begin{tabular}{|l|l|}
\hline Income earned & \% composition \\
\hline $100-1000$ & 45 \\
\hline $1100-2000$ & 25 \\
\hline 2100 and above & 30 \\
\hline
\end{tabular}

Estimating the total income generated by scavengers is constrained by the lack of official figures on the total number of scavengers in Mubi. Attempt to find the total number of scavengers in Mubi was not estimated. Average income of $\mathrm{N} 600$ earned by a scavenger in a day.

\section{Problems of Scavengers.}

One economic problem facing scavengers in Mubi is the issue of multiple taxes levied to them by both the local governments and the state Ministry of Environment. It was discovered government officials harass scavengers and claimed that they are responsible for littering areas. Taxes are levied directly on the salvage dealers. A salvage dealer was quoted to have said "imagine that they (Ministry of environment) are accusing us of littering the place with junks, where as we are the ones who are assisting them in reducing the massive mountains of refuse in the site. Due to the low bargaining power and the unorganized nature of scavenging, part or the entire tax burden is passed to the scavengers. This finding is consistent with that of Adisa (2000) and Muktar (2001). The surplus value analysis as applied by Birbeck (1979) and Singular (1992) have explained this phenomenon.

The health of scavengers is however, vulnerable to disease, as garbage dumps contain sharp objects like home use syringes, razor blade, broken bottles and pieces of metals which could easily harm anyone that is not careful and can result into contacting HIV/AIDS, hepatitis, tetanus or even result to death.

When scavengers were asked whether they need any government assistance, all those interviewed said government should help to provide necessary working materials such as Hand gloves, masks, rubber boots, wheel barrows and small Capital so that their vulnerability to diseases can be reduced and the collection made efficient.

\section{Conclusion}

Waste scavenging in Mubi arises mainly due to the existence of waste dumps and recycling enterprises on one hand, and the income earned as well as poverty on the other hand. Scavenging as an informal activity has employed over 700 people in Mubi. The average monthly income 
earned by a scavenger is found to be above the minimum wage paid by Adamawa State government. The number of children below the age of 15 working as scavengers can be seen as child labour, though poverty is what necessitates them to be engaged. Scavengers have faced problems of multiple taxes and vulnerability to disease, hence they need government assistance.

\section{Recommendations}

One major problem facing scavengers is the informality of their profession and lack of bargaining power. It is recommended that scavengers should form cooperatives so that they can pool their efforts and resources together and bargain collectively, Government and non-governmental organizations should therefore; enlighten them through seminars, and campaigns. Scavenger cooperatives have been practiced in Latin American countries and have succeeded.

The government should mediate on the taxes charged by local governments and the state Ministry of environment so that scavengers can be made to pay a single and realistic tax. Attached to this point is the need for the state government to encourage scavenging and make the profession less vulnerable and more efficient, this can take the form of provision of necessary working equipment's like hand globes, boots, wheel barrows and practitioners financially empowered.

\section{References}

[1] Ayotamuno JM, Gobo AE (2004). Municipal Solid Waste Management in PortHarcout, Nigeria. J. Environ. Manage Qua. 15: 38-47.

Adeoye PA, Sadeeq MA, Musa JJ, Adebayo SE (2011). Solidwaste management in Minna, North Central Nigeria: present practices and future challenges. J. Biodiversity Environ. Sci.,1(6):1-8.

[2] Adeyemi AO (2001). Waste Scavenging in Third World Cities: A Case Study in Ilorin City. Inaugural Lecture, University of Ilorin, Ilorin, Kwara State,

Nigeria. Agunwamba JC (1998). Solid Waste Management in Nigeria: Problems and Issues.Environ. Manag.,22(6):849-856.Crossref

[3] Agwu MO (2012). Issues and Challenges of Solid Waste Management Practices in Port-Harcourt City, Nigeria - a behavioural perspective. Am. J. Soc.

Manag. Sci., 3(2): 83- 92. Crossref

[4] Akpofure RK (2009). Environmental Science: An Int. Res. J. Public Environ. Health 29 Introduction. Kraft Books Limited, Ibadan, Nigeria. Aljaradin M, Persson KM, Sood M (2015). The Role of Informal Sector in Waste Management, A Case Study; Tafila-Jordan. Resources and Environ, 5(1): 9-14.

[5] Mshelia AD (2015). Municipal solid waste scavenging practice's in Mubi, Nigeria. Sky J. Soil Sci. Environ. Manag. 4(4):040 - 045.

[6] Adejobi OS, Olorunnimbe RO (2012). Challenges of Waste Management and Climate Change in Nigeria: Lagos State Metropolis Experience. Afri. J. Sci.

Res. 7 (1): 346-362

*Corresponding author.

E-mail address: allahvallu @gmail.com 